\title{
Fast recovery of lead from hydrochloric acid via a novel silica-supported anion exchange resin for the determination of ${ }^{210} \mathrm{~Pb}$ in environmental samples
}

Lifeng Chen ${ }^{a}$, Jie Zhang ${ }^{b}$, Xianwen He ${ }^{c}$, Manqing Liu ${ }^{c}$, Qiuyang $W^{2} i^{c}$, Xinpeng Wang ${ }^{b, *}$, Yuezhou Wei, ${ }^{a,{ }^{*}}$

a School of Nuclear Science and Engineering, Shanghai Jiao Tong University, 800 Dong Chuan Road, Shanghai 200240, PR China.

${ }^{\mathrm{b}}$ School of Resources, Environment and Materials, Guangxi Key laboratory of Processing for Non-ferrous metallic and Featured Materials, Guangxi University, 100 Daxue Road, Nanning 530004, PR China.

c Radiation-Environment Management and Monitoring Station of Guangxi Zhuang Autonomous Region, 80 Rong Mo Road, Nanning 530222, PR China

* Corresponding author 1: Xinpeng Wang

$\underline{\text { Tel: }+86-771-3224332}$

* Corresponding author 2: Yuezhou Wei

Tel: +86-21-34205684,
Email: wangxinpeng@gxu.edu.cn

Fax: +86-771-3224332

Email: yzwei@sjtu.edu.cn

Fax: $+86-21-3425182$ 
Abstract: The measurement of ${ }^{210} \mathrm{~Pb}$ is significant in environmental studies. Lead separation in $\mathrm{HCl}$ solution is a vital procedure but suffers from poor efficiency with high labor and time costs. To overcome this problem, a novel anion exchange resin was synthesized and characterized by different techniques followed by studies on the adsorption behaviors towards lead in $\mathrm{HCl}$ solution. The results suggest that $\mathrm{SiPS}-\mathrm{N}\left(\mathrm{CH}_{3}\right)_{3} \mathrm{Cl}$ was successfully prepared with small particle size, low water swelling rate, and large specific surface area. The maximum anion exchange capacity resulted from quaternary amine groups was determined to be 1.0 mmol $\left(\mathrm{Cl}^{-}\right) / \mathrm{g}$.The adsorption activities reached equilibrium within 3 min under selected conditions offering extremely fast adsorption kinetics. The synergistic adsorption mechanism, the multilayer adsorption mechanism, and the competition from co-existing chloride anions were found to be responsible for the lead adsorption performance of $\operatorname{SiPS}-\mathrm{N}\left(\mathrm{CH}_{3}\right)_{3} \mathrm{Cl}$. Column experiments showed that the feeding volume of lead and $\mathrm{HCl}$ had impact on the chemical yield regardless of the co-existence of high concentrations of $\mathrm{FeCl}_{3}(90 \mathrm{mM})$ and a high flow speed $(4.0 \mathrm{~mL} / \mathrm{min})$. Based on these results, a separation process integrating SiPS-N $\left(\mathrm{CH}_{3}\right)_{3} \mathrm{Cl}$ and the matched parameters was finally developed and tested. Our work greatly raised the lead separation efficiency in $\mathrm{HCl}$ solutions with implications for measuring ${ }^{210} \mathrm{~Pb}$ in environmental samples.

Keywords: Anion exchange; Silica; Lead-210; Determination; Adsorption kinetics.

\section{Introduction}


${ }^{210} \mathrm{~Pb}\left(\mathrm{t}_{1 / 2}=22.2 \mathrm{y}\right)$ is a radioactive isotope of stable ${ }^{207} \mathrm{~Pb}$ that occurs naturally as one of the decay products of the ${ }^{238} \mathrm{U}$ series. Most ${ }^{210} \mathrm{~Pb}$ is from ${ }^{222} \mathrm{Rn}\left(\mathrm{t}_{1 / 2}=3.8 \mathrm{~d}\right)$ in the atmosphere or lithosphere after a series of decays (passing through ${ }^{218} \mathrm{Po},{ }^{214} \mathrm{~Pb},{ }^{214} \mathrm{Bi}$, and ${ }^{214} \mathrm{Po}$ ). Other sources of ${ }^{210} \mathrm{~Pb}$ include the burning of fossil fuels, the processing of lead ore, and car engines using tetraethyl lead as fuel [1]. ${ }^{210} \mathrm{~Pb}$ leaves the atmosphere quickly by wet washout or dry deposition and readily enters soil or water $[2,3]$. The measurement of ${ }^{210} \mathrm{~Pb}$ is significant for environmental studies, as it provides quantitative information on the flux of ${ }^{222} \mathrm{Rn}$ and its daughter nuclides in the atmosphere [4-6]. Such measurements are applied in uranium exploration, monitoring radionuclide migration in the uranium series, and luminescence dating of sediments [7-9]. ${ }^{210} \mathrm{~Pb}$ and its daughter ${ }^{210} \mathrm{Po}$ have also aroused great public concern because they account for $35 \%$ of the total internal irradiation dose resulting from naturally occurring radionuclides. Such species can accumulate in foods especially seafoods and be ingested by humans [10-12]. The World Health Organization recommends that the activity concentration of ${ }^{210} \mathrm{~Pb}$ be less than $0.1 \mathrm{~Bq} / \mathrm{L}$ in drinking water [2].

The decay of ${ }^{210} \mathrm{~Pb}$ is accompanied by the combined emission of beta particles $(16 \& 63$ $\mathrm{keV})$ and gamma rays $(46.5 \mathrm{keV})$. It then transforms into ${ }^{210} \mathrm{Bi}(5.1 \mathrm{~d})$, which next decays to ${ }^{210} \mathrm{Po}$ by emitting beta particles $(1.2 \mathrm{MeV})$ [13]. The ${ }^{210} \mathrm{Po}$ is a pure alpha-emitter, and the emitted particle energy is $5.3 \mathrm{MeV}$. Direct counting of beta particles emitted by ${ }^{210} \mathrm{~Pb}$ is almost impossible due to the low energy. Generally, four main methods are used to determine ${ }^{210} \mathrm{~Pb}$ including: (1) direct counting of gamma rays of ${ }^{210} \mathrm{~Pb}$ [14], (2) separation of ${ }^{210} \mathrm{Po}$ followed by counting of its alpha activity $[15,16]$, (3) separation of ${ }^{210} \mathrm{Bi}$ followed by 
counting its beta activity [17], and (4) separation of $\mathrm{Pb}$ followed by counting the beta activity of ingrowing ${ }^{210} \mathrm{Bi}[1,3,18]$. These methods have both advantages and disadvantages.

Direct counting of gamma rays suffers from poor sensitivity and accuracy [1]. Method (2) has a long-time delay (at least 6 months) for the secular equilibrium ${ }^{210} \mathrm{~Pb}^{210} \mathrm{Bi}^{210} \mathrm{Po}$. It is also unable to obtain the chemical yield of $\mathrm{Pb}[19] .{ }^{210} \mathrm{Bi}$ separation is selective and sensitive, but it requires equilibrium between ${ }^{210} \mathrm{~Pb}$ and ${ }^{210} \mathrm{Bi}$ in samples and is not yet applicable for some biological and environmental samples [1]. Therefore, the separation of $\mathrm{Pb}$ followed by counting the beta activity of ingrowing ${ }^{210} \mathrm{Bi}$ is the most common method in the field of nuclide analysis due to its easy operation, rapid turnaround time, and excellent selectivity and accuracy.

Although the fourth method saves time versus other determination methods, significant time and labor are still required to separate lead. The brief separation flowsheet of ${ }^{210} \mathrm{~Pb}$ is shown in Fig.1, containing some procedures [20-22]: the addition of stable $\mathrm{Pb}$ as carrier, the coprecipitation with ferric hydroxide, the collection and dissolution of mixed precipitate, the lead purification (including adsorption and desorption) in columns, the evaporation of collected solution, the followed dissolution and final precipitate with sulphates, etc. As a vital procedure, column separation and evaporation occupy a large fraction of the total time and labor costs. The two procedures would last for several days for one sample assuming an 8-hour workday [21]. This is a common problem in radiation environmental monitoring; for example, in the Radiation/Environment Management and Monitoring Station of Guangxi Zhuang Autonomous Region and other similar governmental agencies situated in China. 
These agencies follow the same nuclear industry protocol originated from "Standard Test Method for Lead - 210 in Water" (ASTM D7535 - 2009).

Strong base anion exchange resins are commonly used to separate ${ }^{210} \mathrm{~Pb}$ such as Dowex $1 \times 8$ [7], BIO-RAD-AG 1-X4 [1], and $201 \times 7$ [19]. The separation principle is that the lead cation can compound with chloride ions in the hydrochloric acid solution and then form anionic complexes that could be adsorbed by anion exchange resins; other metal cations like alkalis and alkaline earth metal cations cannot form such a complex. However, these resins suffer from poor adsorption kinetics [23-25], thus leading to a long separation time and low efficiency. More recently, scholars have developed novel anion exchangers for cationic metal-organic framework materials (MOF) [26-28], layered double-metal hydroxides materials (LDH) [29-31], inorganic cationic extended frameworks materials [32, 33], and functionalized graphene oxide materials [34-36]. However, few works have investigated the separation and purification of lead in hydrochloric acid solution. Therefore, whether these anion exchangers could be used to separate ${ }^{210} \mathrm{~Pb}$ is unclear, especially because of the problematic chemical stability or column compatibility of these materials in strong acid. Here, we report the synthesis and characterization of a novel silica-supported anion exchange resin with notable adsorption kinetics, extremely low swelling, and the same chemical properties as traditional anion exchange resins. The adsorption behaviors of this composite in hydrochloric acid were investigated in batch and column modes. As a result, a novel anion exchanger with excellent performance and a matched separation process with the optimum operation parameter were obtained. This system was used to separate lead from hydrochloric acid for 
downstream determination of ${ }^{210} \mathrm{~Pb}$ in environmental samples.

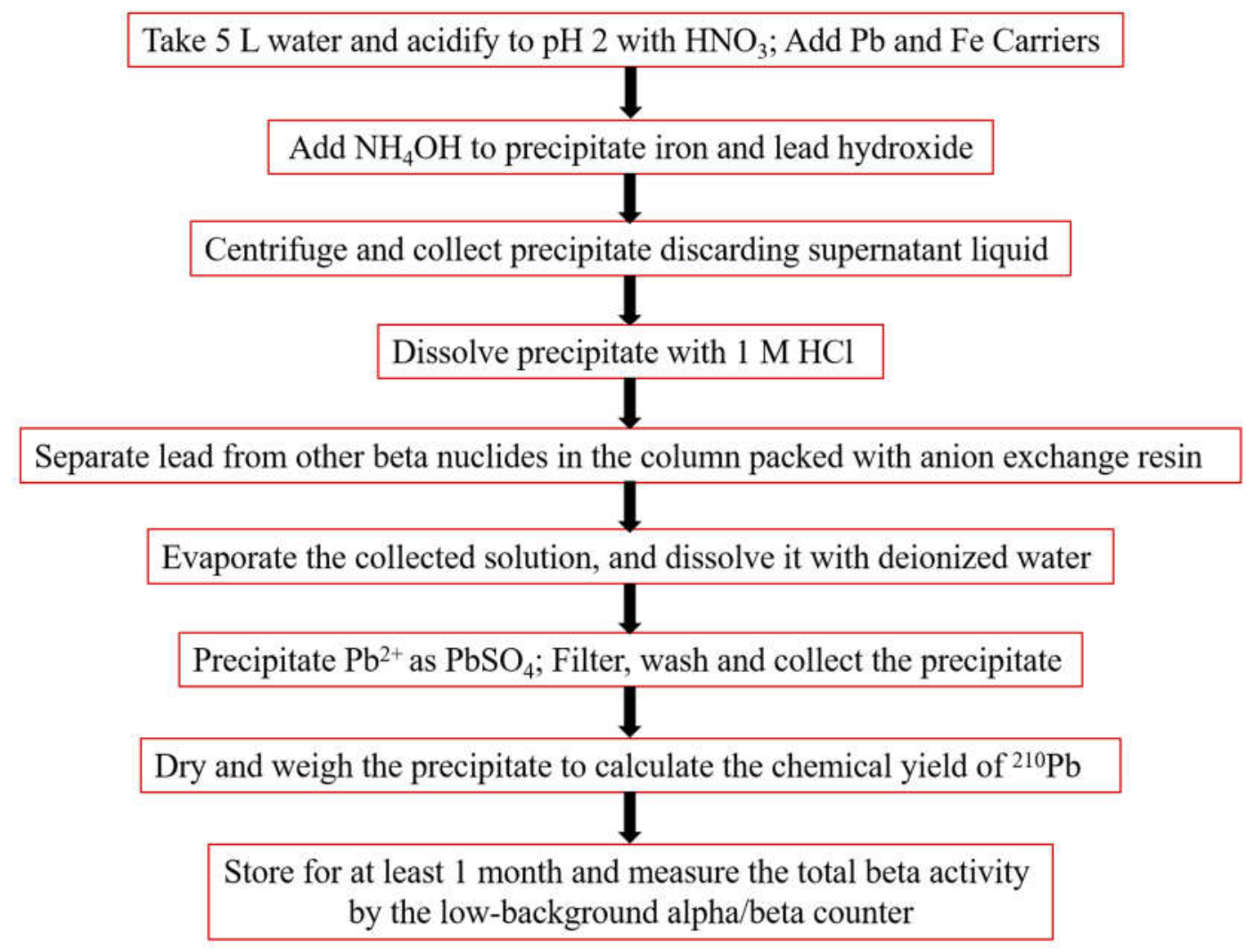

Fig. 1 The separation and purification flowsheet of ${ }^{210} \mathrm{~Pb}$.

\section{Experimental section}

\subsection{Materials and reagents}

The silica used in the work was purchased from Fuji Silysia Chemical Ltd. (Japan). The particle size ranged from 75 to $150 \mu \mathrm{m}$, and the porosity was $69 \%$. The divinyl benzine (DVB) was a m/p-mixture stabilized with $1000 \mathrm{mg} / \mathrm{L}$ tert-butyl-catechol, and the purity was $55 \%$, which needed to be purified by $1 \mathrm{M} \mathrm{NaOH}$ solution in advance to remove the stabilizer. DVB was purchased from Shanghai Aladdin Bio-Chem Technology Co., Ltd. and employed as a crosslinking agent. The initiator $\alpha, \alpha^{\prime}$-azobisisobuty-ronitrile (AIBN; chemical purity) was 
obtained from Tianjin Guangfu Fine Chemical Research Institute. The chloromethyl methyl ether (CMME; analytical purity) was from Chengdu Aike Chemical Reagent Co., Ltd. and used as the chloromethylation reagent. The trimethylamine aqueous solution (TMA; 33 wt.\%) was purchased from Sinopharm Chemical Reagent Co., Ltd. and was used as the amination reagent. Other reagents were of analytical purity grade and were obtained from Shanghai Macklin Biochemical Co., Ltd., including styrene, zinc chloride, acetophenone, and diethyl phthalate (DEP), unless otherwise mentioned. All solutions were prepared with ultrapure water (UPW) with an electrical resistance $>18.2 \mathrm{M} \Omega$. In this work, traditional resins, D201, 732, and IRA900, were used to compare with the synthesized materials and were purchased from Sunresin Company and Shanghai Macklin Biochemical Co., Ltd.

\subsection{Synthesis}

The silica-supported composite anion exchange resin was grafted with a quaternary amine group and was denoted as $\mathrm{SiPS}-\mathrm{N}\left(\mathrm{CH}_{3}\right)_{3} \mathrm{Cl}$. Fig. 2 shows the reaction path of preparation, which is separated into three main procedures: 
<smiles>C=Cc1ccc(C=C)cc1</smiles>

(Divinylbenzene)

$+$
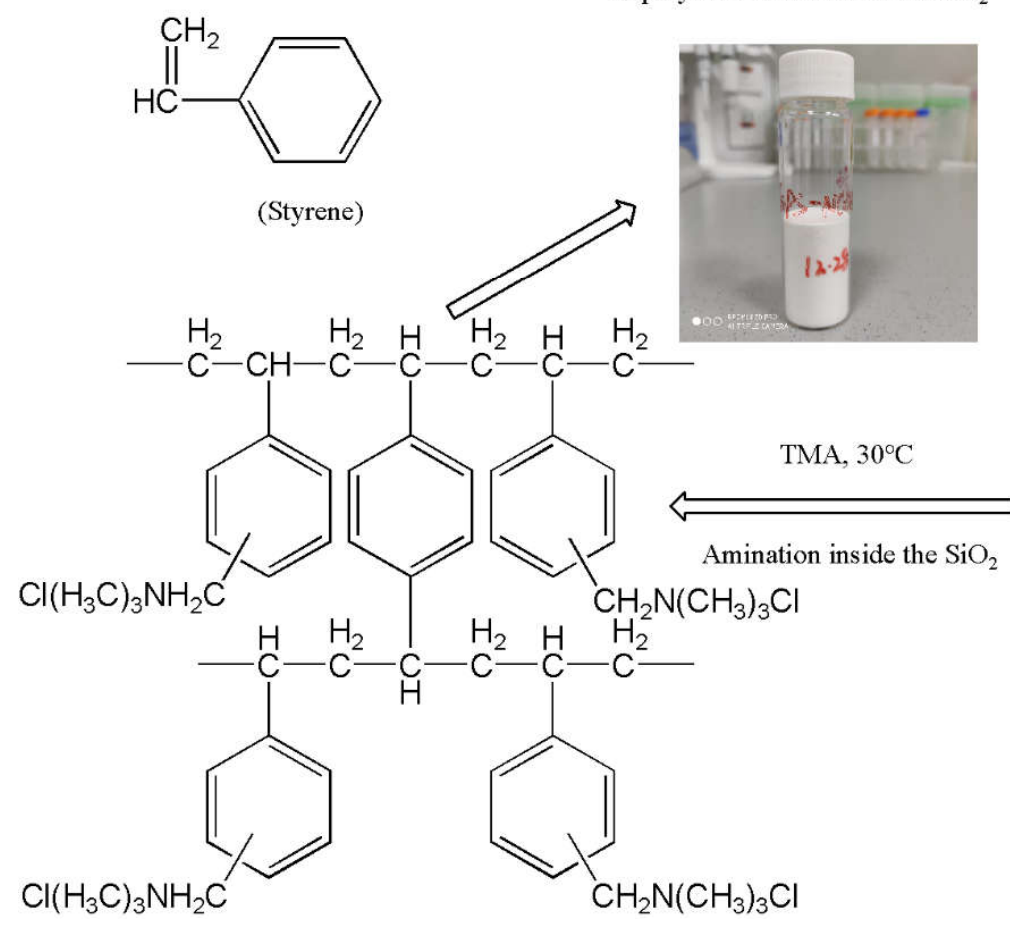

AIBN, ACP and DEP, $90^{\circ} \mathrm{C}$

Copolymerization inside the $\mathrm{SiO}_{2}$
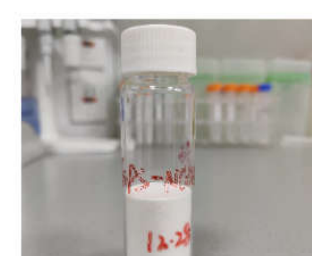<smiles>CCC1CC2CC(CC)C(c3ccccc31)c1ccccc12</smiles><smiles>CCC(C)CC(C)CCC(C)C</smiles><smiles>CC(C)(C)[14CH3]</smiles><smiles>CCC(C)CC(C)CCC(C)C</smiles>

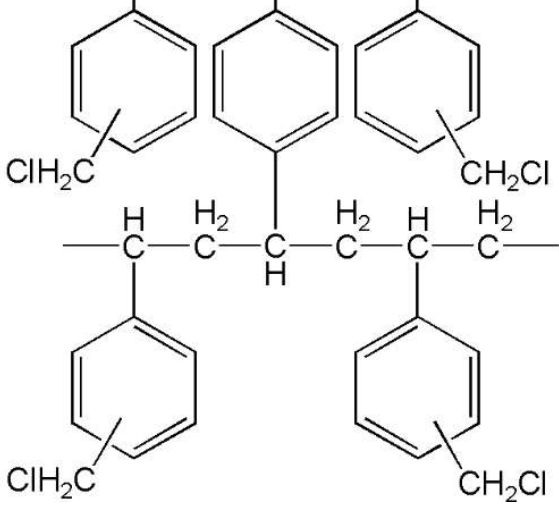

Fig. 2 The chemical reaction path for the synthesis of SiPS-N(CH$)_{3} \mathrm{Cl}$.

(1) Preparation of the silica-supported polystyrene (denoted as SiPS)

The synthesis of SiPS adopted an in situ solution copolymerization method where the DVB and styrene monomers were copolymerized in the mixed diluent of acetophenone and DEP without water. The mixed organic phase was sucked into the pores of silica particles via capillary and differential air pressure. A detailed synthesis has been published[37].

(2) Chloromethylation of SiPS

Here, $40 \mathrm{~g}$ of SiPS and $120 \mathrm{~mL}$ of CMME were added to a three-neck flask fitted with a 
blender, an Allihn condenser, and a dripping funnel. The mixed phases were agitated slowly at room temperature for $3 \mathrm{~h}$. Next, $7.2 \mathrm{~g}$ of $\mathrm{ZnCl}_{2}$ was added in three batches. The flask was then heated in a water bath at $40^{\circ} \mathrm{C}$ for $12 \mathrm{~h}$. The stirring rate was controlled at $90-100 \mathrm{rpm}$, and the condensate temperature was $5^{\circ} \mathrm{C}$. After completing the reaction, the product was named SiPVBC (silica-supported poly-vinylbenzyl chloride) and was washed by UPW and ethanol and finally dried in a vacuum oven at $40^{\circ} \mathrm{C}$ for $48 \mathrm{~h}$. Before this procedure, the optimum ratio of catalyst to CMME was investigated to increase the chlorine content of SiPVBC (Fig. S1). The optimum ratio was then adopted.

(3) The amination of SiPVBC

$40 \mathrm{~g}$ of SiPVBC and $60 \mathrm{~mL}$ of benzene were added into a flask with three necks connected with a blender, an Allihn condenser, and a dropping funnel. The mixed phases were slowly stirred at room temperature for $4 \mathrm{~h}$. Next, $100 \mathrm{~mL}$ of TMA was added into the flask dropwise at $10-20^{\circ} \mathrm{C}$ within $6 \mathrm{~h}$. The mixture was then heated in a water bath at $30^{\circ} \mathrm{C}$ for $12 \mathrm{~h}$ after which $20 \mathrm{~mL}$ of additional TMA was added to continue the reaction for $2 \mathrm{~h}$. The product was separated, washed by ethanol three times, and then placed in a saturated $\mathrm{NaCl}$ solution with $\mathrm{pH}$ adjusted to $2-3$. After $2 \mathrm{~h}$, the saturated $\mathrm{NaCl}$ solution was gradually diluted. The composite resin was then washed by UPW and finally dried in a vacuum oven at $40^{\circ} \mathrm{C}$ for 48 $\mathrm{h}$ before use. The product was denoted as $\mathrm{SiPS}-\mathrm{N}\left(\mathrm{CH}_{3}\right)_{3} \mathrm{Cl}$.

\subsection{Characterization}

These prepared materials were characterized by FT-IR (Shimadzu IR Tracer 100, Japan), 
TG-DSC (Netzsch STA 449F3, Germany), SEM-EDS (Phennom Prox, Holland), BET (TRISTAR II 3020, United States), and elemental analysis (EA, Elementar Vario MICRO cube, Germany). For FT-IR, the spectrum was scanned from $400 \mathrm{~cm}^{-1}$ to $4000 \mathrm{~cm}^{-1}$ via a $\mathrm{KBr}$ disc. The TG-DSC analysis was conducted in an oxygen atmosphere at a flow rate of 20 $\mathrm{mL} / \mathrm{min}$ and a heating rate of $5^{\circ} \mathrm{C} / \mathrm{min}$. For SEM-EDS, the cross section was obtained by immobilizing the composite particles with acrylic resin.

\subsection{The estimation of swelling rate}

Traditional resins D201, 732, and IRA900 were compared with SiPS-N(CH$)_{3} \mathrm{Cl}$ for the bulk density and swelling rate. D201, 732, and IRA900 were pretreated according to the national standard of China GBT5476-1996. Finally, D201 and IRA900 were transformed into Cl-type, and 732 was transformed into Na-type. Next, the apparent volumes per unit mass were measured in a graduated cylinder as described previously [37].

\subsection{The determination of amine groups}

Next, $0.1026 \mathrm{~g}$ of SiPS-N $\left(\mathrm{CH}_{3}\right)_{3} \mathrm{Cl}$ was packed in a glass column $(\phi \times \mathrm{h}=5 \mathrm{~mm} \times 10 \mathrm{~cm})$. The column was first fed with $50 \mathrm{~mL}$ of UPW (this was discarded), and then eluted by $50 \mathrm{~mL}$ of $0.1 \mathrm{M} \mathrm{NaNO}_{3}$ (collected). The amount of chloride ions in the effluent was measured with an ion chromatograph (Metrohm 930, Switzerland). Considering that the amine groups have a high affinity towards $\mathrm{ReO}_{4}^{-}$, the maximum adsorption amount towards the perrhenate anion was further measured by ICP-AES (Shimadzu S7510, Japan). The results suggested that the amount of chloride taken by SiPS- $\mathrm{N}\left(\mathrm{CH}_{3}\right)_{3} \mathrm{Cl}$ and the maximum exchange capacity were both 
about $1.0 \mathrm{mmol} / \mathrm{g}$.

\subsection{The calculation of lead species}

The distribution of lead species was calculated by the PHREEQC software developed by the United States Geological Survey [38]. The thermodynamic data in the database PHREEQC.dat were employed and listed in Table S1.

\subsection{Batch experiments}

The $5000 \mathrm{mg}\left(\mathrm{Pb}^{2+}\right) / \mathrm{L}$ stock solution was prepared by dissolving $0.7993 \mathrm{~g} \mathrm{~Pb}\left(\mathrm{NO}_{3}\right)_{2}$ in $100 \mathrm{~mL}$ of UPW. The working solution of $500 \mathrm{mg}\left(\mathrm{Pb}^{2+}\right) / \mathrm{L}$ was obtained by diluting the stock solution 10-fold. Other stock or working solutions were prepared as mentioned above. The 0.1 $\mathrm{g}$ of SiPS-N($\left(\mathrm{CH}_{3}\right)_{3} \mathrm{Cl}$ was mixed with $5 \mathrm{~mL}$ of working solution in glass bottles. These bottles were covered with Teflon caps and placed in a shaker at room temperature; the shaking frequency was $120 \mathrm{rpm}$. These solutions were subsequently separated by the syringe filter with a mean pore size of $0.45 \mu \mathrm{m}$. The separated solutions were diluted by $1 \%(\mathrm{v} / \mathrm{v}) \mathrm{HCl}$ solution and measured by an atomic absorption spectrophotometer (AAS, Jena contra 700, Germany). The adsorption efficiency and amount were calculated via following two equations:

$$
\begin{gathered}
\left.Q_{e}=\left(C_{0}-C_{e}\right)\right] V / m \\
D=\left(C_{0}-C_{e}\right) / C_{0} \times 100 \%
\end{gathered}
$$

Here, $Q_{e}(\mathrm{mg} / \mathrm{g})$ and $D(\%)$ are the adsorption amount and adsorption efficiency at the equilibrium state, respectively; $C_{0}(\mathrm{mg} / \mathrm{L})$ and $C_{e}(\mathrm{mg} / \mathrm{L})$ represent the initial and equilibrium 
concentration of lead, respectively; $V(\mathrm{~mL})$ is the volume of solution; and $m(\mathrm{~g})$ is the mass of the adsorbent.

The impact of initial concentrations of $\mathrm{HCl}$ and co-existing $\mathrm{FeCl}_{3}$ were investigated to explore the adsorption behaviors of SiPS-N($\left(\mathrm{CH}_{3}\right)_{3} \mathrm{Cl}$ towards lead cations in the $\mathrm{HCl}$. In addition, the adsorption kinetics and isotherms were carefully studied by varying the contact time and the initial concentration of lead, respectively. Here, the pseudo-first order kinetic model (PFO) and the pseudo-second-order kinetic model were employed to fit the kinetic data (see Supporting Material (S2)).

\subsection{Column experiments}

The $3.3579 \mathrm{~g}$ of SiPS-N $\left(\mathrm{CH}_{3}\right)_{3} \mathrm{Cl}$ was packed in a glass column $(\phi \times \mathrm{h}=5 \mathrm{~mm} \times 30 \mathrm{~cm})$ connected with a peristatic pump (EYELA MP 2000, Japan) and an automatic fraction collector (EYELA DC-1500C, Japan); the dead volume was about $5.4 \mathrm{~mL}$. The solution was pumped into the column at a certain speed and then collected by an automatic fraction collector. The column was regenerated by $30 \mathrm{~mL}$ UPW and pretreated with $20 \mathrm{~mL}$ of $\mathrm{HCl}$ (1.0 M) for the next experiment. Namely, the column was used repeatedly. Generally, four column experiments were performed with different aims (see Supporting Material (S3)).

\section{Results and Discussion}

\subsection{Characterization}

The prepared samples were first characterized by TG-DSC analysis. Based on the weight loss, the organic percent of SiPS, SiPVBC, and $\operatorname{SiPS}-\mathrm{N}\left(\mathrm{CH}_{3}\right)_{3} \mathrm{Cl}$ were $17.6 \%, 19.5 \%$, and 
24.6\%, respectively (Fig. 3). The increased organic percent implied effective modification of the precursors. SiPS went through two apparent weight loss stages as the temperature increased from 25 to $650^{\circ} \mathrm{C}$. These stages were accompanied by two exothermic peaks near 311 and $491^{\circ} \mathrm{C}$, respectively, as shown in Fig. 3(a). The two weight loss stages both resulted from the decomposition of the organic bone structure. Compared to SiPS, SiPVBC appeared to have two weight loss stages as shown in Fig. 3(b). However, an exothermic shoulder peak occurred at about $256^{\circ} \mathrm{C}$ in the DSC curve, which could be ascribed to the decomposition of the chloromethyl group. For SiPS-N $\left(\mathrm{CH}_{3}\right)_{3} \mathrm{Cl}$ (Fig. 3(c)), two endothermic and four exothermic peaks appeared with the decomposition process. The first stage started from $25{ }^{\circ} \mathrm{C}$ to $139{ }^{\circ} \mathrm{C}$, which could be attributed to the evaporation of residual water and the loss of methyl on quaternary amine groups based on the endothermic essence. The second weight loss stage occurred from $152^{\circ} \mathrm{C}$ to $240^{\circ} \mathrm{C}$. This stage was also endothermic and could be ascribed to the thermal decomposition of the tertiary amine. The weight loss stages higher than $240^{\circ} \mathrm{C}$ were the oxygenolysis of the organic bone structure. These were supported by the TG-DSC curves of the traditional organic resin D201 (Fig. 3(d)). The decomposition temperature points of D201 were different from those in $\operatorname{SiPS}-\mathrm{N}\left(\mathrm{CH}_{3}\right)_{3} \mathrm{Cl}$ due to the differences in the degree of crosslinking and preparation technology. However, the order of decomposition should be consistent. 

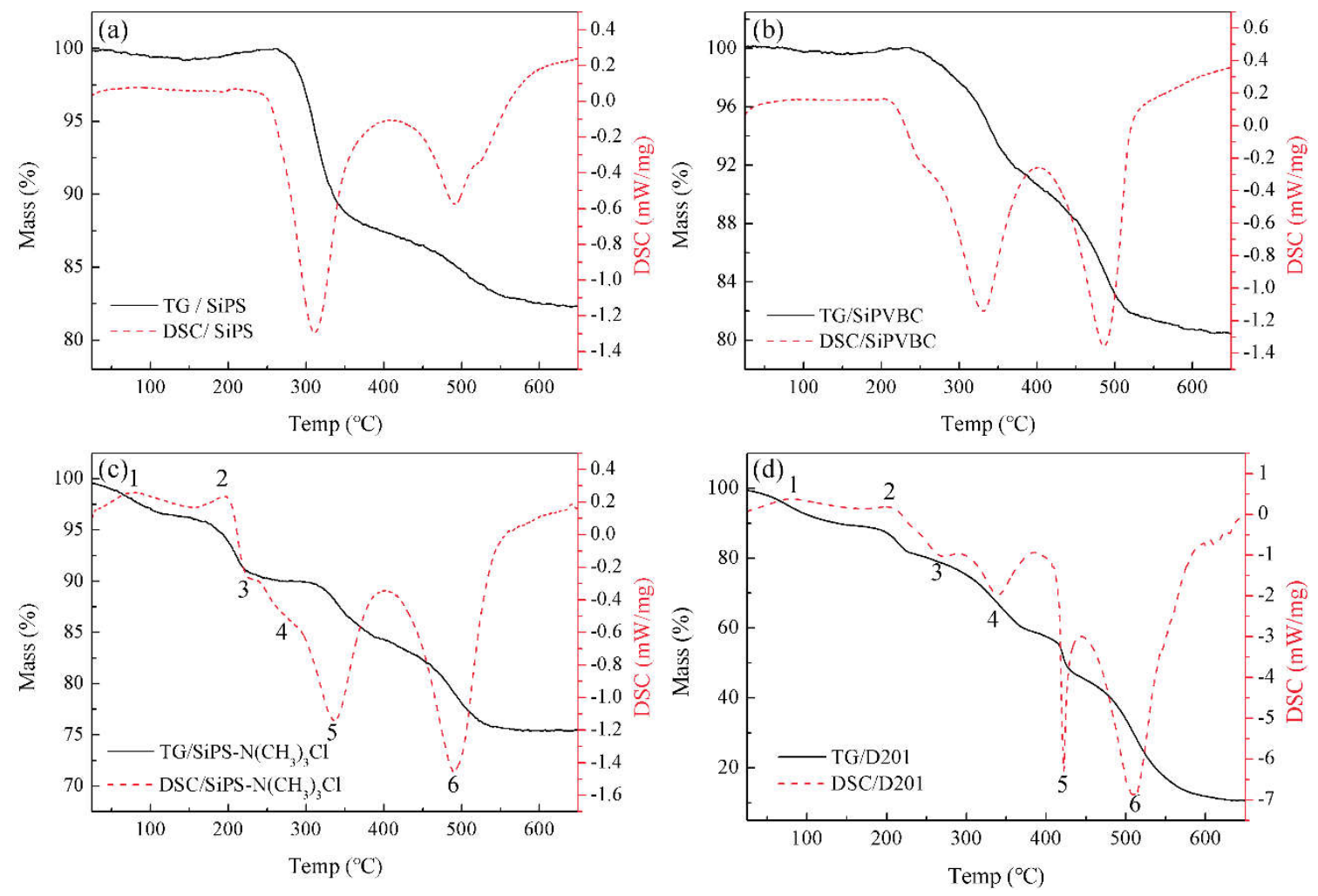

Fig. 3 The TG-DSC curves of SiPS, SiPVBC, SiPS-N $\left(\mathrm{CH}_{3}\right)_{3} \mathrm{Cl}$, and D201.

Elemental analysis was next used to acquire the mass percent of $\mathrm{C} / \mathrm{H} / \mathrm{N}$. Table 1 shows the analysis results of SiPS, SiPVBC, and SiPS-N $\left(\mathrm{CH}_{3}\right)_{3} \mathrm{Cl}$. The mass percent of nitrogen reached $1.3 \%$ after the amination of SiPVBC, which is equal to $0.93 \mathrm{mmol}(\mathrm{N}) / \mathrm{g}$ (SiPS-N $\left.\left(\mathrm{CH}_{3}\right)_{3} \mathrm{Cl}\right)$. This is close to the results obtained in Section 2.5, which suggests that the maximum exchange capacity resulted from quaternary amine was about $1.0 \mathrm{mmol}\left(\mathrm{Cl}^{-}\right) / \mathrm{g}$. These results combined with the thermal analysis mentioned above indicated the successful preparation of the silica-supported anion exchange resin. 
Table 1. The mass percent of $\mathrm{N} / \mathrm{C} / \mathrm{H}$ of different samples.

\begin{tabular}{cccc}
\hline Sample Name & $\mathrm{N}(\%)$ & $\mathrm{C}(\%)$ & $\mathrm{H}(\%)$ \\
\hline $\mathrm{SiPS}$ & 0 & 15.50 & 1.35 \\
$\mathrm{SiPVC}$ & 0.055 & 15.545 & 1.2485 \\
$\mathrm{SiPS}-\mathrm{N}\left(\mathrm{CH}_{3}\right)_{3} \mathrm{Cl}$ & 1.30 & 17.21 & 2.43 \\
\hline
\end{tabular}

To obtain the information on pore structure, the resulting composite resin was further characterized by BET. Fig. 4(a) shows the nitrogen adsorption and desorption isotherms. The nitrogen adsorption and desorption isotherms produced an IUPAC type H1 hysteresis loop indicating a narrow pore diameter distribution and uniform shape of SiPS-N $\left(\mathrm{CH}_{3}\right)_{3} \mathrm{Cl}$. These findings are supported by the results in Fig. 4(b), suggesting that the pore diameter was mainly concentrated in the range of $10 \mathrm{~nm}$ to $70 \mathrm{~nm}$; the micropores and macropores only occupied a small portion. The pore parameters obtained by the BET analysis are reported in Table 2. The pore volume decreased from $\mathrm{SiO}_{2}$ to $\mathrm{SiPS}$ to $\mathrm{SiPS}-\mathrm{N}\left(\mathrm{CH}_{3}\right)_{3} \mathrm{Cl}$ due to the increased organic components. The BET surface area of SiPS-N $\left(\mathrm{CH}_{3}\right)_{3} \mathrm{Cl}$ was $59.03 \mathrm{~m}^{2} / \mathrm{g}$, which was much larger than that of traditional resin $732\left(2.82 \mathrm{~m}^{2} / \mathrm{g}\right)$ and IRA900 $\left(7.21 \mathrm{~m}^{2} / \mathrm{g}\right)$ [37]. The average pore diameter was $32.58 \mathrm{~nm}$, suggesting that $\mathrm{SiPS}-\mathrm{N}\left(\mathrm{CH}_{3}\right)_{3} \mathrm{Cl}$ was mesoporous. Generally, the implantation of the silica framework and the in-situ solution polymerization method gives this material possess a large specific surface area that is rich in pore structure. 

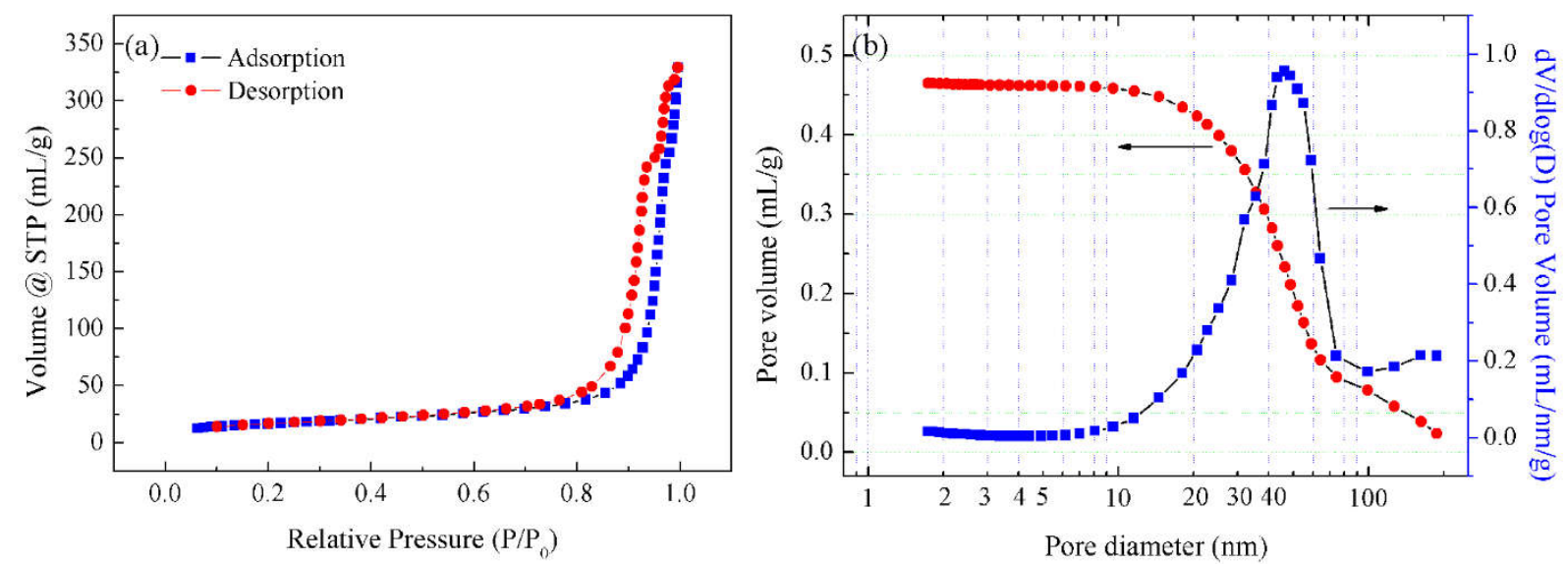

Fig. 4 Nitrogen adsorption and desorption isotherms (a) and the pore diameter distribution (b) of SiPS-N $\left(\mathrm{CH}_{3}\right)_{3} \mathrm{Cl}$.

Table 2 The parameters of pore structure for different materials.

\begin{tabular}{cccc}
\hline Sample name & $\begin{array}{c}\text { BET surface area } \\
\left(\mathrm{m}^{2} / \mathrm{g}\right)\end{array}$ & $\begin{array}{c}\text { Pore volume } \\
(\mathrm{mL} / \mathrm{g})\end{array}$ & $\begin{array}{c}\text { Average pore diameter } \\
(\mathrm{nm})\end{array}$ \\
\hline $\mathrm{SiO}_{2}$ & 80.4 & 1.02 & 50.3 \\
$\mathrm{SiPS}$ & 95.72 & 0.6158 & 26.20 \\
$\mathrm{SiPS}-\mathrm{N}\left(\mathrm{CH}_{3}\right)_{3} \mathrm{Cl}$ & 59.03 & 0.4651 & 32.58 \\
\hline
\end{tabular}

To demonstrate that SiPS-N $\left(\mathrm{CH}_{3}\right)_{3} \mathrm{Cl}$ had anion exchange capability, $1 \mathrm{M} \mathrm{NaNO}_{3}$ solution was used to transform the SiPS-N $\left(\mathrm{CH}_{3}\right)_{3} \mathrm{Cl}$ resin into the SiPS-N $\left(\mathrm{CH}_{3}\right)_{3} \mathrm{NO}_{3}$ type. The SiPS$\mathrm{N}\left(\mathrm{CH}_{3}\right)_{3} \mathrm{NO}_{3}$ was then exchanged with $\mathrm{ReO}_{4}{ }^{-}$anions. SiPS-N $\left(\mathrm{CH}_{3}\right)_{3} \mathrm{NO}_{3}$ and the $\mathrm{ReO}_{4}^{-}-$loaded control were both washed with copious water in the columns and finally prepared into $\mathrm{KBr}$ pellets with $\mathrm{SiO}_{2}$ and $\mathrm{SiPS}-\mathrm{N}\left(\mathrm{CH}_{3}\right)_{3} \mathrm{Cl}$ for FT-IR characterization (Fig. 5).

SiPS-N $\left(\mathrm{CH}_{3}\right)_{3} \mathrm{Cl}$ exhibited almost the same characteristic peaks as $\mathrm{SiO}_{2}$ even though they were different materials. Considering that the organic percent of $\mathrm{SiPS}-\mathrm{N}\left(\mathrm{CH}_{3}\right)_{3} \mathrm{Cl}$ was only $24.6 \%$, and $\mathrm{SiO}_{2}$ had strong and wide characteristic peaks, the chemical information from the 
organic components may be shielded. Moreover, the organic component was impregnated inside the $\mathrm{SiO}_{2}$ and may be also responsible for such results. Similar phenomena were observed previously [25]. However, the characteristic peak of $\mathrm{NO}_{3}{ }^{-}$appeared at $1386 \mathrm{~cm}^{-1}$ in the FT-IR spectrum of SiPS-N $\left(\mathrm{CH}_{3}\right)_{3} \mathrm{NO}_{3}[39-41]$. After the $\mathrm{ReO}_{4}{ }^{-}$exchange, the characteristic peak of $\mathrm{NO}_{3}^{-}$disappeared and the characteristic peak of $\mathrm{ReO}_{4}^{-}$was observed at $916 \mathrm{~cm}^{-1}$ [42-44]. These results demonstrated that the prepared $\mathrm{SiPS}-\mathrm{N}\left(\mathrm{CH}_{3}\right)_{3} \mathrm{Cl}$ resin had the same anion exchange ability as traditional anion exchange resins.

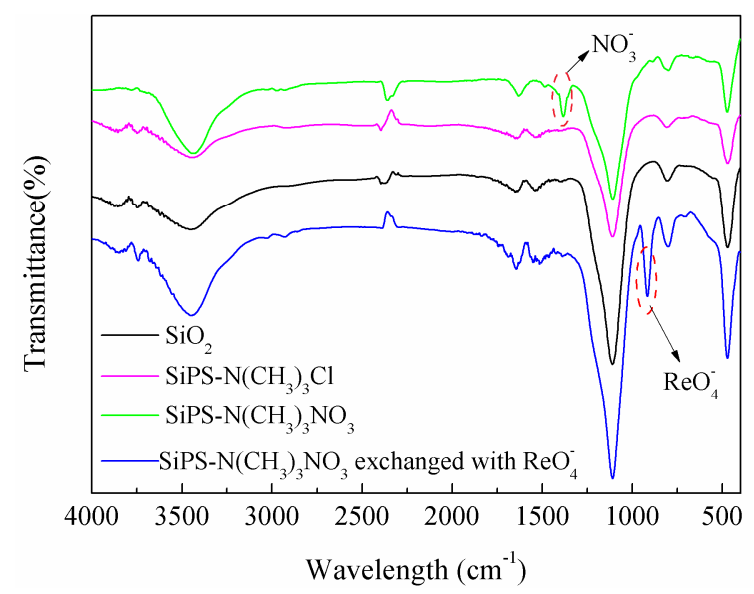

Fig. 5 The FT-IR spectrum of different samples.

SEM-EDS was used to examine the surface morphologies and the cross section of SiPS-N(CH$)_{3} \mathrm{Cl}$. Fig. 6(a) and Fig. 6(b) show that SiPS-N($\left(\mathrm{CH}_{3}\right)_{3} \mathrm{Cl}$ exhibited a uniform shape and smooth surface morphologies. The particle sizes were estimated to be in the range of 75-150 $\mu \mathrm{m}$, which is consistent with $\mathrm{SiO}_{2}$. The magnified surface in Fig. 6(c) appears rugged and rich in mesopores. To determine whether the $\mathrm{SiO}_{2}$ framework was successfully implanted into the organic resin, EDS scans were completed towards the cross section of SiPS-N $\left(\mathrm{CH}_{3}\right)_{3} \mathrm{Cl}$ loaded with $\mathrm{ReO}_{4}^{-}$. Fig. 6(d) shows that the adsorbed $\mathrm{ReO}_{4}^{-}$was uniformly 
distributed in the $\mathrm{SiO}_{2}$ cross section; nitrogen was also detected. These results imply that the $\mathrm{SiO}_{2}$ framework had been implanted into the organic resin by an in situ solution polymerization method. In addition, diffusion from the solution to the inner pores was also observed, indicating the relation of particle size to diffusion distance. A small particle size likely leads to a short diffusion distance and thus improved adsorption kinetics.
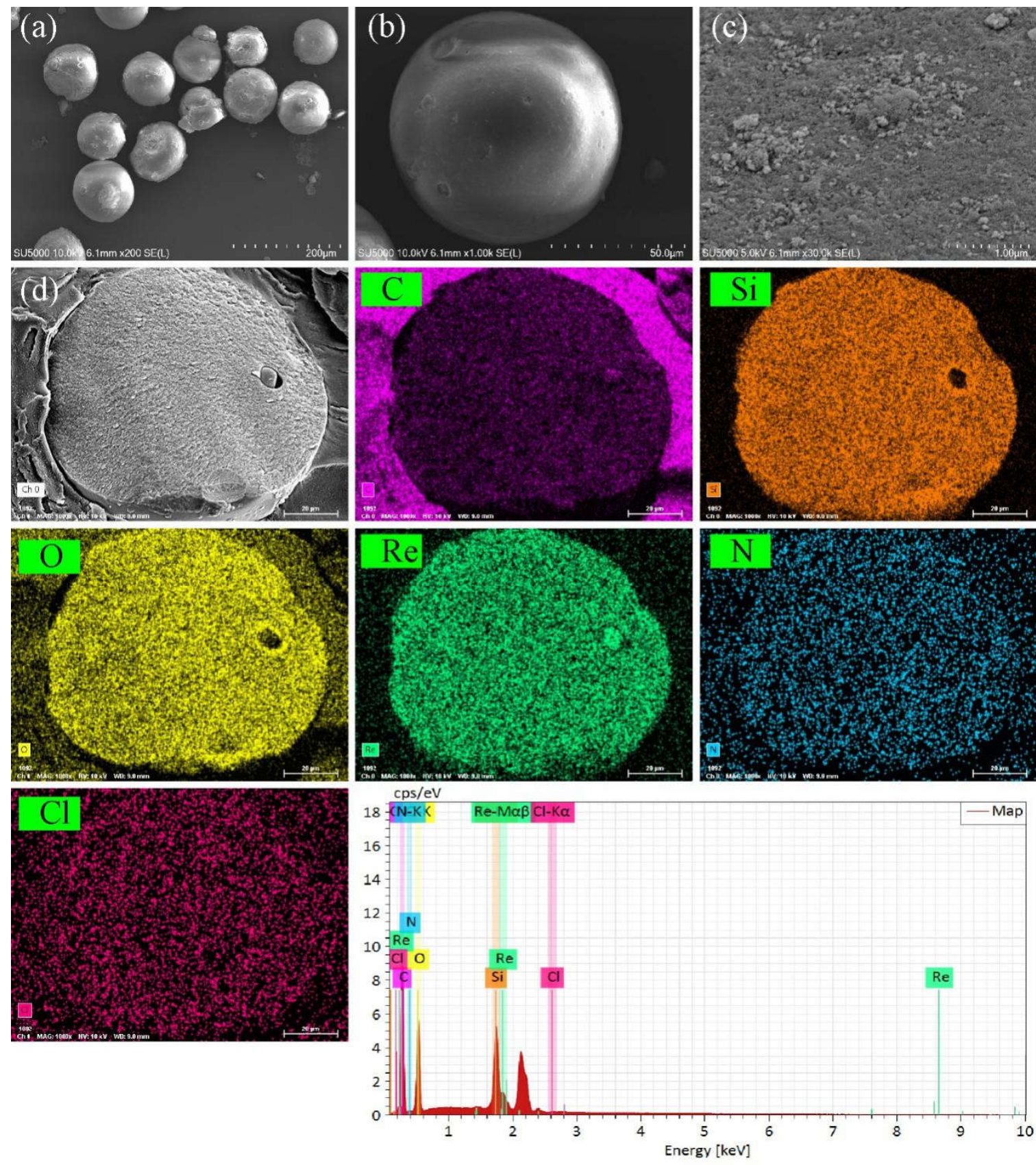
Fig. 6 Surface morphologies and EDS scanning towards the cross section of SiPS-N(CH$)_{3} \mathrm{Cl}$.

\subsection{Apparent volume and swelling rate}

Organic resins are usually grafted with hydrophilic functional groups. They readily adsorb water and swell. High water swelling usually contributes to poor mechanical properties and high column pressure drops [24, 37], which hampers chromatographic performance. In addition, the swelling rate often changes with salt concentration and type, thus making the resin volume inconstant. Therefore, the water swelling rate was estimated by the measurement of apparent volume in a dry and wet state. Fig. 7 shows that SiPS-N $\left(\mathrm{CH}_{3}\right)_{3} \mathrm{Cl}$ exhibited almost the same apparent volume in the dry and wet state, suggesting that the water swelling rate was close to 0 . The excellent anti-swelling property shows great promise in the chromatographic columns. In comparison, the apparent volume increased greatly from the dry state to the wet state for other resins such as D201, IRA900, and 732, indicating the large water swelling rate. Thus, we conclude that the implantation of the silica framework could effectively confine the water swelling of traditional organic resins.

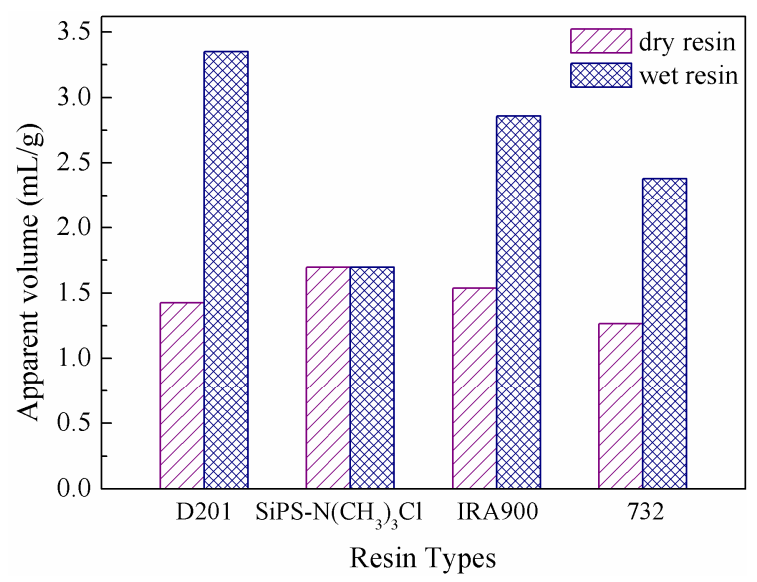

Fig. 7 Apparent volume of dry and wet resins. 


\subsection{Batch experiments}

The lead speciation in different concentrations of hydrochloric acid was calculated by PHREEQC software to better understand the lead adsorption behavior of SiPS-N( $\left(\mathrm{CH}_{3}\right)_{3} \mathrm{Cl}$. As shown in Fig. 8(a), the main lead species in hydrochloric acid included $\mathrm{PbCl}^{+}, \mathrm{Pb}^{2+}, \mathrm{PbCl}_{2}$, $\mathrm{PbCl}_{4}{ }^{2-}$, and $\mathrm{PbCl}_{3}{ }^{-}$. With increasing $\mathrm{HCl}$ concentration, the proportion of electropositive $\mathrm{PbCl}^{+}$and $\mathrm{Pb}^{2+}$ gradually decreased while the $\mathrm{PbCl}_{3}{ }^{-}$increased. For $\mathrm{PbCl}_{4}{ }^{2-}$, the percent first increased and then decreased. At $1 \mathrm{M} \mathrm{HCl}$, the proportion of lead species could be ordered as follows: $\mathrm{PbCl}^{+}(41.3 \%)>\mathrm{PbCl}_{2}(24.9 \%)>\mathrm{PbCl}_{3}{ }^{-}(19.1 \%)>\mathrm{PbCl}_{4}{ }^{2-}(11.2)>\mathrm{Pb}^{2+}(3.5)$, and the electronegative lead-chloride complexes merely occupied $30.3 \%$ of the total lead.

Fig. 8(b) investigated the adsorption behavior of $\mathrm{SiPS}-\mathrm{N}\left(\mathrm{CH}_{3}\right)_{3} \mathrm{Cl}$ towards lead in different concentrations of $\mathrm{HCl}$. The optimum concentration of $\mathrm{HCl}$ was $1.0 \mathrm{M}$ for the adsorption of lead. A lower or higher $\mathrm{HCl}$ concentration would decrease the adsorption efficiency. The thermodynamic calculation suggested that the electronegative lead-chloride complexes occupied $30.3 \%$ of the total lead in $1 \mathrm{M} \mathrm{HCl}$, but the maximum adsorption efficiency was lower than $20 \%$. This indicated that competitive adsorption occurred between the electronegative lead-chloride complexes and the chloride anions. Therefore, the increased proportion of electronegative lead-chloride complexes dominated the adsorption mechanism at lower concentrations while the competitive adsorption dominated at higher concentrations.

The separation of lead usually requires high concentrations of $\mathrm{FeCl}_{3}$ due to the coprecipitation with lead cations. Therefore, the effect of $\mathrm{FeCl}_{3}$ on the adsorption efficiency of lead was studied in $1 \mathrm{M} \mathrm{HCl}$. Fig. 8(c) shows that the increasing concentration of $\mathrm{FeCl}_{3}$ 
had minor effects on the adsorption efficiency of lead; this declined less than $3 \%$ even though the concentration of $\mathrm{FeCl}_{3}$ approached $200 \mathrm{mM}$. The competitive adsorption with the chloride anion and the ferric-chloride complex anion may be responsible for the $3 \%$ decline in adsorption efficiency. In addition, this experiment indicated that $\mathrm{SiPS}-\mathrm{N}\left(\mathrm{CH}_{3}\right)_{3} \mathrm{Cl}$ has a relatively higher affinity to the lead-chloride complex anion than the ferric-chloride complex anion and the chloride anion because the lead concentration was much lower than the ferric and chloride ion.

Fig. 8(d) illustrates the adsorption isotherm of lead in $1 \mathrm{M} \mathrm{HCl}$ solution. The adsorption efficiency rose gradually with the increase of initial lead concentration. Apparently, the loaded lead-chloride complex anions improved the adsorption performance (increased adsorption efficiency), indicating the occurrence of the synergistic adsorption mechanism. This kind of adsorption isotherm could be classified into "S" type [45], which could not be fitted with the frequently-used Langmuir and Freundlich equations. The "S" type adsorption isotherm revealed that the adsorption of lead-chloride complex anion faced an intense competition by the chloride anion for the active sites, which was also supported by Fig. 8(b) and Fig. 8(c). The maximum adsorption amount towards lead exceeded $13 \mathrm{mg} / \mathrm{g}$.

The adsorption kinetics were investigated in Fig. 8(e) and Fig. 8(f). As seen in Fig. 8(e), the adsorption requires $30 \mathrm{~min}$ to achieve the equilibrium state at a concentration of $500 \mathrm{mg}$ $\left(\mathrm{Pb}^{2+}\right) / \mathrm{L}$. The equilibrium time shortens to 3 min at a higher concentration of $1000 \mathrm{mg}(\mathrm{Pb}) / \mathrm{L}$. These results suggested that the SiPS-N $\left(\mathrm{CH}_{3}\right)_{3} \mathrm{Cl}$ had superior adsorption kinetics towards lead in $\mathrm{HCl}$ solution, and confirmed the formation of the synergistic adsorption, which 
reduced the equilibrium time at a higher concentration of lead. The pseudo first-order kinetic model and the pseudo second-order kinetic model were employed to fit the experimental data. The R square values and the fitting results of PSO were found to be better than that of PFO, implying that the adsorption activities were controlled by chemical reactions. The parameters obtained are listed in Table 3. 

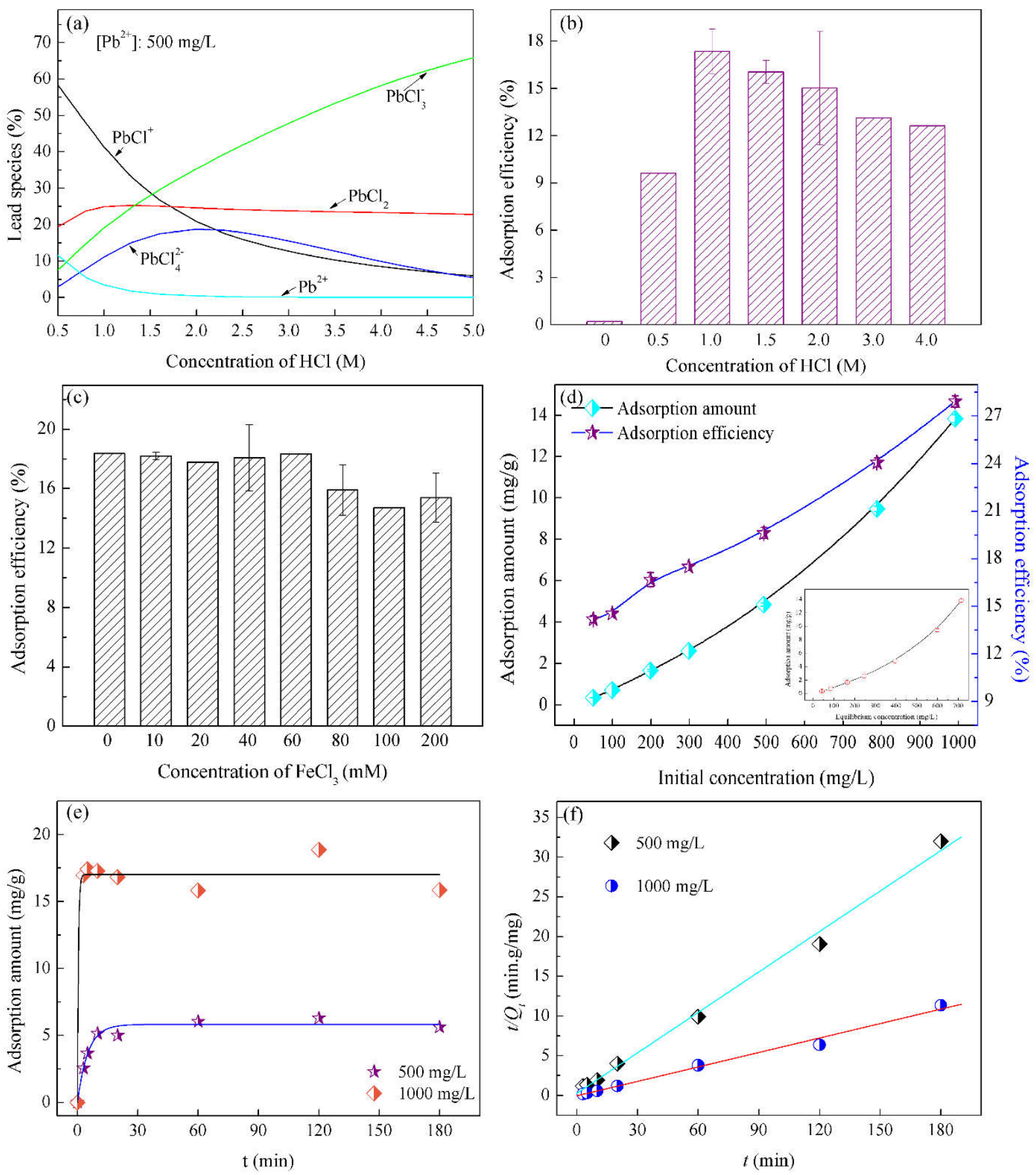

Fig.8 Lead species distribution (a) and the effects of $\mathrm{HCl}$ concentration (b), $\mathrm{FeCl}_{3}$ concentration (c), initial lead concentration (d), and the contacting time (e, f) on the adsorption lead adsorption performance of SiPS-N(CH3) $)_{3} \mathrm{Cl}$. Experimental conditions: (b) $\mathrm{t}=$ $1 \mathrm{~h},\left[\mathrm{~Pb}^{2+}\right]=500 \mathrm{mg} / \mathrm{L} ;(\mathrm{c}) \mathrm{t}=1 \mathrm{~h},\left[\mathrm{~Pb}^{2+}\right]=500 \mathrm{mg} / \mathrm{L},[\mathrm{HCl}]=1.0 \mathrm{M} ;(\mathrm{d}) \mathrm{t}=1 \mathrm{~h},[\mathrm{HCl}]=1.0$ $\mathrm{M} ;(\mathrm{e})$ and $(\mathrm{f})[\mathrm{HCl}]=1.0 \mathrm{M}$. 
Table 3. The parameters obtained by fitting PFO and PSO.

\begin{tabular}{cccccccc}
\hline \multirow{2}{*}{$\begin{array}{c}\mathrm{Pb}^{2+} \\
\text { Concentration } \\
(\mathrm{mg} / \mathrm{L})\end{array}$} & $Q_{e(\text { exp })}(\mu \mathrm{g} / \mathrm{g})$ & & \multicolumn{4}{c}{$\mathrm{PFO}$} & \multicolumn{2}{c}{ PSO } \\
\cline { 3 - 7 } & & $Q_{e}(\mu \mathrm{g} / \mathrm{g})$ & $k_{1}\left(\mathrm{~min}^{-1}\right)$ & $R^{2}$ & $Q_{e}(\mu \mathrm{g} / \mathrm{g})$ & $k_{2}\left(\mu \mathrm{g} \cdot \mathrm{g}^{-1} \cdot \mathrm{min}^{-1}\right)$ & $R^{2}$ \\
\hline 500 & 5.987 & 5.812 & 0.1950 & 0.9696 & 5.891 & 0.1044 & 0.9935 \\
1000 & 15.85 & 17.01 & 2.0324 & 0.9711 & 16.49 & -0.06436 & 0.9882 \\
\hline
\end{tabular}

\subsection{Column experiments for the establishment of the separation process}

Static adsorption efficiency of SiPS-N(CH$)_{3} \mathrm{Cl}$ towards lead was approximately $18 \%$ in 1 $\mathrm{M} \mathrm{HCl} \mathrm{solution,} \mathrm{and} \mathrm{thus} \mathrm{column} \mathrm{separation} \mathrm{was} \mathrm{the} \mathrm{exclusive} \mathrm{method} \mathrm{to} \mathrm{realize} \mathrm{the}$ quantitative recovery of lead, because the dynamic adsorption in columns could be regarded as the combination of numerous static adsorption processes. The breakthrough curve in $1 \mathrm{M}$ $\mathrm{HCl}$ was first studied. As shown in Fig. 9(a), lead was effectively immobilized by SiPS-N $\left(\mathrm{CH}_{3}\right)_{3} \mathrm{Cl}$ when the volume of effluent was less than $30 \mathrm{~mL}$. After that, the concentration of lead climbed gradually and then approached the feeding concentration. Considering that the adsorbed lead-chloride anions improve the adsorption performance of SiPS-N $\left(\mathrm{CH}_{3}\right)_{3} \mathrm{Cl}$, a higher concentration may lead to a better result, i.e., more lead is adsorbed. However, the volume of influent was still controlled within $25 \mathrm{~mL}$ for the recovery of lead, which also coincided with the real situation.

Fig. 9(b) shows the elution results of $1 \mathrm{M} \mathrm{HCl}$ solution to the lead-loaded columns. A small amount of lead was eluted from the $\mathrm{HCl}$, and more $\mathrm{HCl}$ will contribute to the desorption 
of lead, due to the intense competition between chloride anions and lead-chloride complex anions. To obtain a high recovery rate, the volume of $\mathrm{HCl}$ used for the elusion should be controlled within $10 \mathrm{~mL}$.

Fig. 9(c) details the effect of flow speed on the lead recovery. The flow speed had minor effects on the lead recovery rate. Flow speeds of $1.0 \mathrm{~mL} / \mathrm{min}$ and $2.0 \mathrm{~mL} / \mathrm{min}$ led to consistent adsorption/desorption curves. A higher rate of $4.0 \mathrm{~mL} / \mathrm{min}$ showed the similar adsorption curves, but the concentration distribution of lead became more dispersive. However, lead was concentrated within $15 \mathrm{~mL}$ of effluent from the volume point of 30 to $45 \mathrm{~mL}$ regardless of the difference in flow speed. $2.0 \mathrm{~mL} / \mathrm{min}$ was finally selected as the optimum flow speed for the experiments to protect the soft tubes.

The mixed solution containing $90 \mathrm{mM}$ of $\mathrm{FeCl}_{3}$ was also allowed to flow through the regenerated and pretreated column. The results are shown in Fig. 9(d) and confirmed that lead in the mixed solution was still effectively immobilized by the column even though it co-existed with high concentration of $\mathrm{FeCl}_{3}$. In addition, the change in solution color suggested that the collected solution (the last four tubes) had few ferric cations, indicating that lead could be separated from other cations by this method and material under real conditions. Table S2 lists the chemical yield of lead obtained in Fig. 9(c) and Fig. 9(d). Generally, the flow speed and the co-existence of $\mathrm{FeCl}_{3}$ had minor effects on the chemical yield of lead in 1 $\mathrm{M} \mathrm{HCl}$ solution, because the chemical yields of lead all exceeded $95 \%$ under different conditions. 

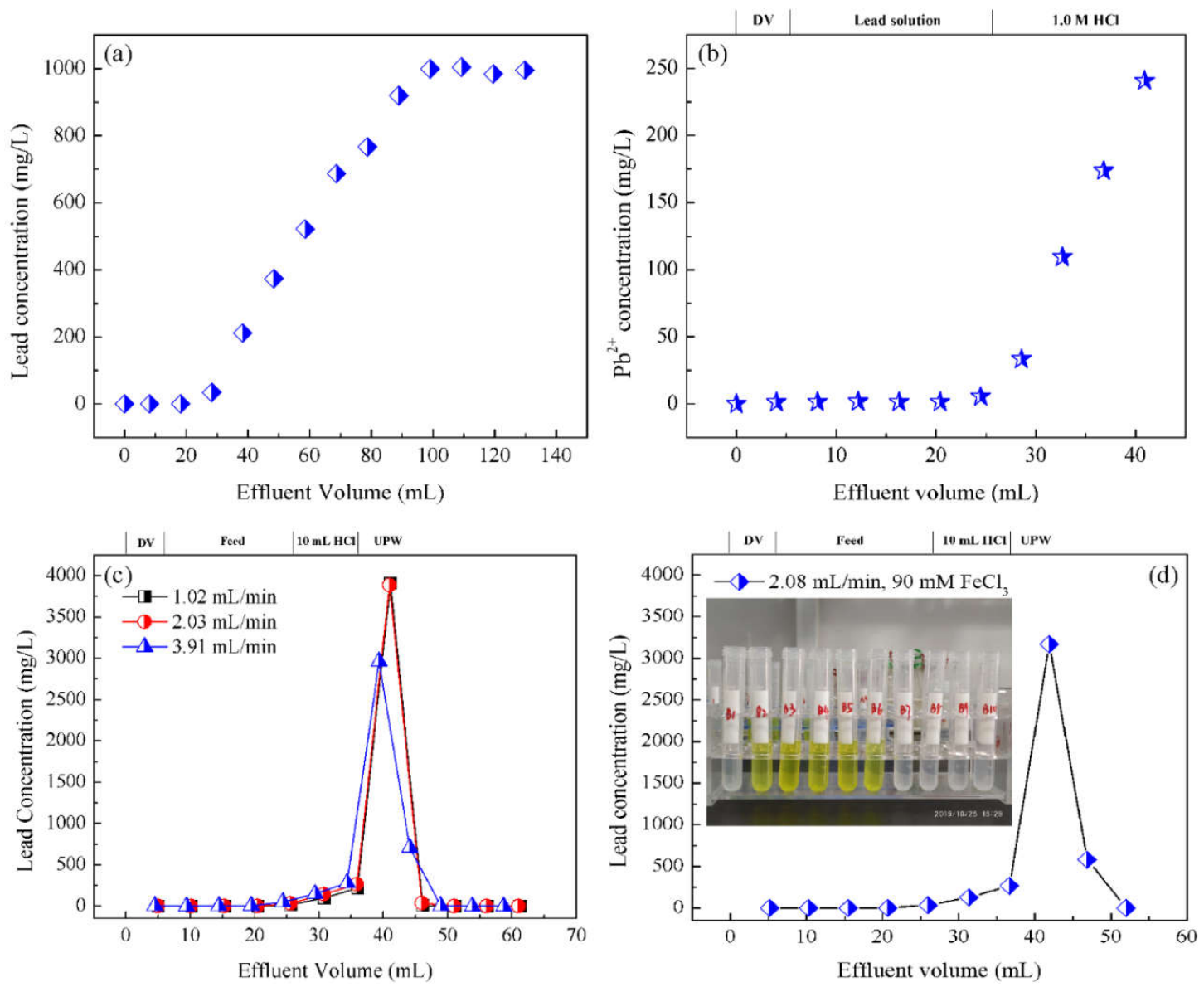

Fig.9 (a) The breakthrough curve of lead in $1.0 \mathrm{M} \mathrm{HCl}$; (b) Effect of $\mathrm{HCl}(1.0 \mathrm{M})$ volume on the lead concentration in the effluent; (c) Effect of flow speed on the chemical yield of lead; (d) effect of $\mathrm{FeCl}_{3}$ on the chemical yield of lead. Experimental conditions: $m$ (resin) $=3.3579$ g, column $\phi \times h=5 \mathrm{~mm} \times 30 \mathrm{~cm}$; Flow speed (a) $=2.0 \mathrm{~mL} / \mathrm{min}$, Flow speed (b) $=1.0 \mathrm{~mL} / \mathrm{min}$.

Based on the results mentioned-above, a separation process integrated the optimum operation parameters: the mixed solution containing ${ }^{210} \mathrm{~Pb}$ and its stable isotope ${ }^{207} \mathrm{~Pb}$ (should be less than $25 \mathrm{~mL})$ was first allowed to flow through the column $(\phi \times \mathrm{h}=5 \mathrm{~mm} \times 30 \mathrm{~cm})$ packed with SiPS-N(CH$)_{3} \mathrm{Cl}$ at a speed of $2.0 \mathrm{~mL} / \mathrm{min}$; Next, $10 \mathrm{~mL}$ of $1 \mathrm{M} \mathrm{HCl}$ solution was pumped to elute the residual ions; As followed, $15 \mathrm{~mL}$ of UPW was fed to desorb the lead, and the automatic fraction collector started to collect simultaneously. For the convenience of 
comparison, Table 4 lists the technological parameters for the different recovery processes. The parameters of this work were superior to those reported by others $[19,21,46]$. The separation time could be controlled within 30 minutes while those of others were much longer.

Table 4 Comparison of technological parameters among different recovery processes.

\begin{tabular}{ccccccc}
\hline Ref. & Resin type & Column dimension & $\mathrm{V}_{\text {feeding }}(\mathrm{mL})$ & $\mathrm{V}_{\mathrm{HCl}}(\mathrm{mL})$ & $\mathrm{V}_{\mathrm{UPW}}(\mathrm{mL})$ & $v(\mathrm{~mL} / \mathrm{min})$ \\
\hline$[19]$ & $201 \times 7$ & $13 \mathrm{~mm} \times 25 \mathrm{~cm}$ & 50 & $10 \sim 20$ & 40 & $0.5^{\mathrm{a}} / 0.1^{\mathrm{d}}$ \\
{$[46]$} & BIO-RAG-AG 1-X4 & $13 \mathrm{~mm} \times 25 \mathrm{~cm}$ & 24 & 35 & 50 & $0.5^{\mathrm{a} / 0.5^{\mathrm{d}}}$ \\
{$[21]$} & $201 \times 7$ & Not mentioned & $14-17$ & 140 & 80 & $0.1^{\mathrm{a}} / 0.1^{\mathrm{d}}$ \\
This work & $\mathrm{SiPS}-\mathrm{N}\left(\mathrm{CH}_{3}\right)_{3} \mathrm{Cl}$ & $5 \mathrm{~mm} \times 30 \mathrm{~cm}$ & $14-25$ & 10 & 15 & $2.0^{\mathrm{a}} / 2.0^{\mathrm{d}}$ \\
\hline
\end{tabular}

${ }^{a}$ denotes the flow speed for adsorption; ${ }^{d}$ denotes the flow speed for washing and desorption; $\mathrm{V}$ denotes the volume; $v$ represents flow speed.

The process was finally tested by the Radiation-Environment Management and Monitoring Station of Guangxi Zhuang Automatic Region with real environmental water samples. The results were shown in Table 5 and compared with those obtained by $201 \times 7$ using the common process. Here, two environmental water samples A and B were collected near a uranium mining site in Guangxi Province and duplicated twice. It was found that the chemical yield of lead for the two water samples all exceeded $95 \%$ for $201 \times 7$ and SiPS-N $\left(\mathrm{CH}_{3}\right)_{3} \mathrm{Cl}$. The radioactivity concentrations obtained by $\mathrm{SiPS}-\mathrm{N}\left(\mathrm{CH}_{3}\right)_{3} \mathrm{Cl}$ were 5.65 and $25.4 \mathrm{mBq} / \mathrm{L}$ for samples $\mathrm{A}$ and $\mathrm{B}$, respectively, which were close to those obtained by $201 \times 7$ based on the industrial standard. These demonstrates that the developed 
silica-supported anion exchange resin and the matched process could be used to determine

${ }^{210} \mathrm{~Pb}$ in environmental samples.

Table 5 The radioactivity concentration of ${ }^{210} \mathrm{~Pb}$ in different water samples collected in Guangxi province.

\begin{tabular}{|c|c|c|c|c|c|c|c|c|}
\hline & $\begin{array}{l}\text { Collecting } \\
\text { Location }\end{array}$ & $\begin{array}{l}\text { Sample } \\
\text { type }\end{array}$ & $\begin{array}{l}\text { Added lead } \\
\text { carrier (mg) }\end{array}$ & $\begin{array}{l}\text { Lead } \\
\text { recovered } \\
(\mathrm{mg})\end{array}$ & $\begin{array}{l}\text { Chemical } \\
\text { yield }(\%)\end{array}$ & $\begin{array}{l}\text { Measured radioactivity } \\
\text { concentration of }{ }^{210} \mathrm{~Pb} \\
(\mathrm{mBq} / \mathrm{L})\end{array}$ & Resin used & $\begin{array}{l}\text { Separation } \\
\text { process }\end{array}$ \\
\hline A & 脚古冲 & $\begin{array}{l}\text { Lake } \\
\text { water }\end{array}$ & 9.750 & 10.430 & 107 & 5.8 & $201 \times 7$ & $\begin{array}{l}\text { Industrial } \\
\text { standard }\end{array}$ \\
\hline B & 总排口 & $\begin{array}{l}\text { Waste } \\
\text { water }\end{array}$ & 9.750 & 10.140 & 101 & 27.7 & $201 \times 7$ & $\begin{array}{l}\text { Industrial } \\
\text { standard }\end{array}$ \\
\hline A & 脚古冲 & $\begin{array}{l}\text { Lake } \\
\text { water }\end{array}$ & 9.750 & 9.848 & 104 & 5.65 & $\mathrm{SiPS}-\mathrm{N}\left(\mathrm{CH}_{3}\right)_{3} \mathrm{Cl}$ & This work \\
\hline B & 总排口 & $\begin{array}{l}\text { Waste } \\
\text { water }\end{array}$ & 9.750 & 9.653 & 99 & 25.4 & $\mathrm{SiPS}-\mathrm{N}\left(\mathrm{CH}_{3}\right)_{3} \mathrm{Cl}$ & This work \\
\hline
\end{tabular}

\section{Conclusion}

This work developed a novel silica-supported anion exchange resin with superior exchange kinetics and the same chemical performance as traditional anion exchange resin. Compared to typical anion exchange resins, such as D201 and IRA900, the SiPS-N(CH$)_{3} \mathrm{Cl}$ had smaller particle sizes $(75-150 \mu \mathrm{m})$, a much lower water swelling rate $(0 \%)$, and a larger specific surface area $\left(59.03 \mathrm{~m}^{2} / \mathrm{g}\right)$. The maximum anion exchange capacity resulted from quaternary amine groups was determined to be $1.0 \mathrm{mmol}\left(\mathrm{Cl}^{-}\right) / \mathrm{g}$.

Batch results suggested that lead adsorption by SiPS-N $\left(\mathrm{CH}_{3}\right)_{3} \mathrm{Cl}$ faced strong competition from the chloride anion, leading to low adsorption efficiencies $(\leq 18 \%)$ in the $\mathrm{HCl}$ solution even at the optimum concentration $(1.0 \mathrm{M})$. The concentration of lead was found related to the 
equilibrium time due to the occurrence of synergistic adsorption indicated by the " $\mathrm{S}$ " type adsorption isotherm. The equilibration time required for $500 \mathrm{mg}\left(\mathrm{Pb}^{2+}\right) / \mathrm{L}$ and $1000 \mathrm{mg}$ $\left(\mathrm{Pb}^{2+}\right) / \mathrm{L}$ was about $30 \mathrm{~min}$ and $3 \mathrm{~min}$, respectively. The concentration of co-existing $\mathrm{FeCl}_{3}$ had little effect on the adsorption efficiency of lead, which declined less than $3 \%$, with the $\mathrm{FeCl}_{3}$ concentration reaching to $200 \mathrm{mM}$. The adsorption isotherm of $\left.\mathrm{SiPS}-\mathrm{N}_{(\mathrm{CH}}\right)_{3} \mathrm{Cl}$ suggested that the adsorption efficiency increased gradually with increasing lead equilibrium concentration. This is different from the commonly-observed adsorption isotherms and indicated the occurrence of synergistic adsorption as well as the multilayer adsorption mechanism.

The column results suggested that the feeding volume of lead solution and $\mathrm{HCl}$ solution (for eluting the residual ions) should be strictly controlled due to the important effect on the chemical yield of lead, and the lead recovery could be performed at a speed of $4.0 \mathrm{~mL} / \mathrm{min}$ regardless of the co-existing high concentrations of $\mathrm{FeCl}_{3}$. Based on these results, a separation process integrating this novel material and the matched parameters was developed and tested with actual environmental water samples. The results showed that $\operatorname{SiPS}-\mathrm{N}\left(\mathrm{CH}_{3}\right)_{3} \mathrm{Cl}$ could quickly separate the lead from the mixed solution derived from environmental water samples with chemical yields exceeding 95\%; the time was controlled to within 30 minutes. Furthermore, the radioactivity concentrations obtained by this separation process were quite close to those obtained by $201 \times 7$ using the common separation process.

In conclusion, $\mathrm{SiPS}-\mathrm{N}\left(\mathrm{CH}_{3}\right)_{3} \mathrm{Cl}$ is an excellent alternative to traditional anion exchange resins. This material and protocol show promise and significance in the determination of ${ }^{210} \mathrm{~Pb}$ 
in environmental samples.

\section{Acknowledgements}

This work was supported by the National Natural Science Foundation of China [grant number 21866007] and the Open Foundation of Guangxi Key Laboratory of Processing for Nonferrous Metals, and Featured Materials of Guangxi University (grant number gxysof1808). The authors would like to acknowledge the help of Lingyu Lu in the Radiation-Environment Management and Monitoring Station of Guangxi Zhuang Autonomous Region.

\section{Notes}

The authors declare no competing financial interests.

\section{Reference}

[1] G. Jia, Simultaneous determination of ${ }^{210} \mathrm{Po}$ and ${ }^{210} \mathrm{~Pb}$ in solid samples: A new method for (210)Pb determination, Appl Radiat Isot 137 (2018) 12-17. 10.1016/j.apradiso.2018.02.019.

[2] N. Aslan, G. Özçayan, Adsorptive removal of lead-210 using hydroxyapatite nanopowders prepared from phosphogypsum waste, Journal of Radioanalytical and Nuclear Chemistry 319 (2019) 1023-1028. 10.1007/s10967-018-6388-x.

[3] E.-S. Ibrahim Shabana, M. Mohammad Taher Qutub, A. Abdulrahman Kinsara, Accumulation of Lead-210 and Polonium-210 in the Groundwater of Wadi Nu'man, Mecca Province, Arabian Journal for Science and Engineering 41 (2016) 4217-4224. 10.1007/s13369-016-2161-z.

[4] N.H. Harley, P. Chittaporn, I.M. Fisenne, P. Perry, 222Rn decay products as tracers of indoor and outdoor aerosol particle size, Journal of Environmental Radioactivity 51 (2000) 27-35. https://doi.org/10.1016/S0265-931X(00)00042-4. 
[5] M.-A. Mélières, M. Pourchet, S. Richard, Surface air concentration and deposition of lead-210 in French Guiana: two years of continuous monitoring, Journal of Environmental Radioactivity 66 (2003) 261-269. https://doi.org/10.1016/S0265-931X(02)00111-X.

[6] M. Baskaran, $\mathrm{Po}-210$ and $\mathrm{Pb}-210$ as atmospheric tracers and global atmospheric $\mathrm{Pb}-210$ fallout: a Review, Journal of Environmental Radioactivity 102 (2011) 500-513. https://doi.org/10.1016/j.jenvrad.2010.10.007.

[7] Y. Ebaid, A. Khater, Determination of ${ }^{210} \mathrm{~Pb}$ in environmental samples, Journal of Radioanalytical and Nuclear Chemistry 270 (2006) 609-619. 10.1007/s 10967-006-0470-5.

[8] K. Meusburger, P. Porto, L. Mabit, C. La Spada, L. Arata, C. Alewell, Excess Lead-210 and Plutonium-239+240: Two suitable radiogenic soil erosion tracers for mountain grassland $\begin{array}{lllll}\text { sites, } & \text { Environmental } & \text { Research } & 160 & \text { (2018) }\end{array}$ https://doi.org/10.1016/j.envres.2017.09.020.

[9] H. Yang, P.G. Appleby, Use of lead-210 as a novel tracer for lead ( $\mathrm{Pb}$ ) sources in plants, Scientific Reports 6 (2016) 21707. 10.1038/srep21707.

[10] G.J. Ham, B.T. Wilkins, L.W. Ewers, ${ }^{210} \mathrm{~Pb},{ }^{210} \mathrm{Po},{ }^{226} \mathrm{Ra}$, U and Th in Arable Crops and Ovine Liver: Variations in Concentrations in the United Kingdom and Resultant Doses, Radiation Protection Dosimetry 93 (2001) 151-159. 10.1093/oxfordjournals.rpd.a006423.

[11] Z. Pietrzak-Flis, E. Chrzanowski, S. Dembinska, Intake of ${ }^{226} \mathrm{Ra},{ }^{210} \mathrm{~Pb}$ and ${ }^{210} \mathrm{Po}$ with food in Poland, Science of The Total Environment 203 (1997) 157-165. https://doi.org/10.1016/S0048-9697(97)00144-7.

[12] J.L. Smith-Briggs, E.J. Bradley, M.D. Potter, The ratio of lead-210 to polonium-210 in U.K. diet, Science of The Total Environment 54 (1986) 127-133. https://doi.org/10.1016/0048-9697(86)90260-3.

[13] L.-J. Pan, G.-B. Yu, Z. Chen, L.-S. Sheng, X.G. Xu, A modified sampling preparation method for rapid determination of $\mathrm{Pb}-210$ radioactivity in plants in China using crown ether and liquid scintillation counting of beta particles, Journal of Radioanalytical and Nuclear 
Chemistry 317 (2018) 565-570. 10.1007/s10967-018-5919-9.

[14] J.P. Bolivar, R. García-Tenorio, M. García-León, Radioactive impact of some phosphogypsum piles in soils and salt marshes evaluated by $\gamma$-ray spectrometry, Applied $\begin{array}{lllll}\text { Radiation } & \text { and } & \text { Isotopes } & 47 & \text { (1996) }\end{array}$ https://doi.org/10.1016/S0969-8043(96)00108-X.

[15] J. Paatero, J. Hatakka, R. Mattsson, Y. Viisanen, Analysis of Daily $210 \mathrm{~Pb}$ Air Concentrations in Finland, 1967-1996, Radiation Protection Dosimetry 77 (1998) 191-198. 10.1093/oxfordjournals.rpd.a032310.

[16] D.I. Strumińska-Parulska, G. Olszewski, J. Falandysz, ${ }^{210} \mathrm{Po}$ and ${ }^{210} \mathrm{~Pb}$ bioaccumulation and possible related dose assessment in parasol mushroom (Macrolepiota procera), Environmental Science and Pollution Research $24 \quad$ (2017) 26858-26864. $10.1007 / \mathrm{s} 11356-017-0458-4$.

[17] D. Desideri, F. Guerra, M.A. Meli, C. Testa, Determination of ${ }^{210} \mathrm{~Pb}$ in sediments by extraction chromatography, Journal of Radioanalytical and Nuclear Chemistry 200 (1995) 385-396. 10.1007/bf02162880.

[18] E.E. Santos, D.C. Lauria, E.C.S. Amaral, E.R. Rochedo, Daily ingestion of ${ }^{232} \mathrm{Th},{ }^{238} \mathrm{U}$, ${ }^{226} \mathrm{Ra},{ }^{228} \mathrm{Ra}$ and ${ }^{210} \mathrm{~Pb}$ in vegetables by inhabitants of Rio de Janeiro City, Journal of $\begin{array}{lllll}\text { Environmental } & \text { Radioactivity } & 62 & \text { (2002) }\end{array}$ https://doi.org/10.1016/S0265-931X(01)00152-7.

[19] G. Jia, M. Belli, S. Liu, U. Sansone, C. Xu, S. Rosamilia, X. Xiao, S. Gaudino, L. Chen, H. Yang, The fractionation and determination procedures for the speciation of $210 \mathrm{~Pb}$ and ${ }^{210}$ Po in soil samples, Analytica Chimica Acta 562 (2006) 51-58. 10.1016/j.aca.2006.01.058.

[20] G. Jia, M. Belli, M. Blasi, A. Marchetti, S. Rosamilia, U. Sansone, ${ }^{210} \mathrm{~Pb}$ and ${ }^{210} \mathrm{Po}$ determination in environmental samples, Applied Radiation and Isotopes 53 (2000) 115-120.

[21] P. Liu, J. Shan, D. Xiao, F. Xiao, H. Wang, J. Shu, H. Yang, The Specific Activity and Balance's Measuring of ${ }^{226} \mathrm{Ra},{ }^{210} \mathrm{~Pb}$ and ${ }^{210} \mathrm{Po}$ in Hengyang Specific Water Environment, 
Nuclear Electronics \& Detection Technology 38 (2018) 43-59.

[22] L. Xue-hong, Z. Qiang, W. Qian, L. Mao-dan, S.M. amp, Application of ${ }^{210} \mathrm{~Pb}$ Analysis Method in Aerosol Determination of Chengdu, Sichuan Environment 36 (2017) 142-146.

[23] C. Xiao, M.A. Silver, S. Wang, Metal-organic frameworks for radionuclide sequestration from aqueous solution: a brief overview and outlook, Dalton Trans 46 (2017) 16381-16386.

[24] L. Chen, X. Yin, Q. Yu, L. Siming, F. Meng, S. Ning, X. Wang, Y. Wei, Rapid and selective capture of perrhenate anion from simulated groundwater by a mesoporous silica-supported anion exchanger, Microporous and Mesoporous Materials 274 (2019) 155-162. 10.1016/j.micromeso.2018.07.029.

[25] L. Chen, Y. Chen, X. Wang, Y. Wei, L. He, F. Tang, A novel silica-based anion exchange resin used for removing uranium from drinking water, Journal of Radioanalytical \& Nuclear Chemistry 314 (2017) 2569-2578.

[26] L. Zhu, D. Sheng, C. Xu, X. Dai, M.A. Silver, J. Li, P. Li, Y. Wang, Y. Wang, L. Chen, Identifying the Recognition Site for Selective Trapping of ${ }^{99} \mathrm{TcO}_{4}^{-}$in a Hydrolytically Stable and Radiation Resistant Cationic Metal-Organic Framework, Journal of the American Chemical Society 139 (2017) 14873-14876. https://doi.org/10.1021/jacs.7b08632.

[27] R.J. Drout, K. Otake, A.J. Howarth, T. Islamoglu, L. Zhu, C. Xiao, S. Wang, O.K. Farha, Efficient Capture of Perrhenate and Pertechnetate by a Mesoporous Zr Metal-Organic Framework and Examination of Anion Binding Motifs, Chemistry of Materials 30 (2018) 1277-1284. https://doi.org/10.1021/acs.chemmater.7b04619.

[28] D. Sheng, L. Zhu, C. Xu, C. Xiao, Y. Wang, Y. Wang, L. Chen, J. Diwu, J. Chen, Z. Chai, Efficient and Selective Uptake of $\mathrm{TcO}_{4}^{-}$by a Cationic Metal-Organic Framework Material with Open $\mathrm{Ag}^{+}$Sites, Environmental Science \& Technology $51 \quad$ (2017) 3471. https://doi.org/10.1021/acs.est.7b00339.

[29] C. Li, Y. Wei, X. Wang, X. Yin, Efficient and rapid adsorption of iodide ion from aqueous solution by porous silica spheres loaded with calcined Mg-Al layered double hydroxide, 
Journal of the Taiwan Institute of Chemical Engineers 85 (2018) 193-200. https://doi.org/10.1016/j.jtice.2018.01.044.

[30] Y. Wang, H. Gao, Compositional and structural control on anion sorption capability of layered double hydroxides (LDHs), Journal of Colloid and Interface Science 301 (2006) 19-26. https://doi.org/10.1016/j.jcis.2006.04.061.

[31] G. Sheng, Y. Tang, W. Linghu, L. Wang, J. Li, H. Li, X. Wang, Y. Huang, Enhanced immobilization of $\mathrm{ReO}_{4}{ }^{-}$by nanoscale zerovalent iron supported on layered double hydroxide via an advanced XAFS approach: Implications for $\mathrm{TcO}_{4}{ }^{-}$sequestration, Applied Catalysis B Environmental 192 (2016) 268-276. https://doi.org/10.1016/j.apcatb.2016.04.001.

[32] S. Wang, E.V. Alekseev, J. Diwu, W.H. Casey, B.L. Phillips, W. Depmeier, T.E. AlbrechtSchmitt, NDTB-1: A Supertetrahedral Cationic Framework That Removes $\mathrm{TcO}_{4}^{-}$from Solution, Angewandte Chemie International Edition 49 (2010) 1057-1060. doi:10.1002/anie.200906397.

[33] S. Wang, P. Yu, B.A. Purse, M.J. Orta, J. Diwu, W.H. Casey, B.L. Phillips, E.V. Alekseev, W. Depmeier, D.T. Hobbs, T.E. Albrecht-Schmitt, Selectivity, Kinetics, and Efficiency of Reversible Anion Exchange with $\mathrm{TcO}_{4}{ }^{-}$in a Supertetrahedral Cationic Framework, Advanced Functional Materials 22 (2012) 2241-2250. 10.1002/adfm.201103081.

[34] Y. Xiong, X. Cui, P. Zhang, Y. Wang, Z. Lou, W. Shan, Improving Re(VII) Adsorption on Diisobutylamine-Functionalized Graphene Oxide, Acs Sustainable Chemistry \& Engineering 5 (2016) 1010-1018. https://doi.org/10.1021/acssuschemeng.6b02322.

[35] J.H. Chen, H.T. Xing, H.X. Guo, W. Weng, S.R. Hu, S.X. Li, Y.H. Huang, X. Sun, Z.B. $\mathrm{Su}$, Investigation on the adsorption properties of $\mathrm{Cr}(\mathrm{VI})$ ions on a novel graphene oxide (GO) based composite adsorbent, Journal of Materials Chemistry A 2 (2014) 12561-12570. 10.1039/C4TA02004A.

[36] C. He, Z. Yang, J. Ding, Y. Chen, X. Tong, Y. Li, Effective removal of Cr(VI) from aqueous solution by 3-aminopropyltriethoxysilane-functionalized graphene oxide, Colloids 
and Surfaces A: Physicochemical and Engineering Aspects 520 (2017) 448-458. https://doi.org/10.1016/j.colsurfa.2017.01.086.

[37] X. Wang, Z. Ye, L. Chen, Q. Zheng, C. Liu, S. Ning, A. Khayambashi, Y. Wei, Microporous silica-supported cation exchanger with superior dimensional stability and outstanding exchange kinetics, and its application in element removal and enrichment, Reactive and Functional Polymers 142 (2019) 87-95. 10.1016/j.reactfunctpolym.2019.06.007.

[38] Z. Ye, X. Yin, L. Chen, X. He, Z. Lin, C. Liu, S. Ning, X. Wang, Y. Wei, An integrated process for removal and recovery of $\mathrm{Cr}(\mathrm{VI})$ from electroplating wastewater by ion exchange and reduction-precipitation based on a silica-supported pyridine resin, Journal of Cleaner Production 236 (2019) 117631. 10.1016/j.jclepro.2019.117631.

[39] Y. Peng, F. Annabi-Bergaya, T. Qi, M. Fan, Z. Liu, J. Zhu, H. He, T. Chen, A combined study by XRD, FTIR, TG and HRTEM on the structure of delaminated Fe-intercalated/pillared clay, Journal of Colloid and Interface Science 324 (2008) 142-149. https://doi.org/10.1016/j.jcis.2008.04.076.

[40] M. Islam, R. Patel, Nitrate sorption by thermally activated $\mathrm{Mg} / \mathrm{Al}$ chloride hydrotalcite-like compound, Journal of Hazardous Materials 169 (2009) 524-531. https://doi.org/10.1016/j.jhazmat.2009.03.128.

[41] Q. Hu, N. Chen, C. Feng, W.W. Hu, Nitrate adsorption from aqueous solution using granular chitosan-Fe ${ }^{3+}$ complex, Applied Surface Science 347 (2015) 1-9. https://doi.org/10.1016/j.apsusc.2015.04.049.

[42] I.A. Miniakhmetov, S.A. Semenov, V.Y. Musatova, A.M. Reznik, Solvent extraction of rhenium with N-(2-hydroxy-5-nonylbenzyl)- $\beta$-hydroxyethylmethylamine, Russian Journal of Inorganic Chemistry 58 (2013) 1380-1382. 10.1134/s0036023613110144.

[43] M. Jia, H. Cui, W. Jin, L. Zhu, Y. Liu, J. Chen, Adsorption and separation of rhenium(VII) using N-ethylimidazolium functionalized strong basic anion exchange resin, Journal of Chemical Technology \& Biotechnology 88 (2013) 437-443. https://doi.org/10.1002/jctb.3904. 
[44] B.M. Marković, Z.M. Vuković, V.V. Spasojević, V.B. Kusigerski, V.B. Pavlović, A.E. Onjia, A.B. Nastasović, Selective magnetic GMA based potential sorbents for molybdenum and rhenium sorption, Journal of Alloys and Compounds 705 (2017) 38-50. https://doi.org/10.1016/j.jallcom.2017.02.108.

[45] C.H. Giles, D. Smith, A. Huitson, A general treatment and classification of the solute adsorption isotherm. I. Theoretical, Journal of Colloid and Interface Science 47 (1974) 755-765. https://doi.org/10.1016/0021-9797(74)90252-5.

[46] G. Jia, G. Torri, Determination of $210 \mathrm{~Pb}$ and $210 \mathrm{Po}$ in soil or rock samples containing refractory matrices, Applied Radiation and Isotopes 65 (2007) 1-8. https://doi.org/10.1016/j.apradiso.2006.05.007. 


\section{Caption of Figures}

Fig. 1 The separation and purification flowsheet of ${ }^{210} \mathrm{~Pb}$.

Fig. 2 The chemical reaction path for the synthesis of SiPS-N($\left(\mathrm{CH}_{3}\right)_{3} \mathrm{Cl}$.

Fig. 3 The TG-DSC curves of SiPS, SiPVBC, SiPS-N(CH 3$)_{3} \mathrm{Cl}$, and D201.

Fig. 4 Nitrogen adsorption and desorption isotherms (a) and the pore diameter distribution (b) of $\operatorname{SiPS}-\mathrm{N}\left(\mathrm{CH}_{3}\right)_{3} \mathrm{Cl}$.

Fig. 5 The FT-IR spectrum of different samples.

Fig. 6 Surface morphologies and EDS scanning towards the cross section of SiPS-N(CH$)_{3} \mathrm{Cl}$.

Fig. 7 Apparent volume of dry and wet resins.

Fig.8 Lead species distribution (a) and the effects of $\mathrm{HCl}$ concentration (b), $\mathrm{FeCl}_{3}$ concentration (c), initial lead concentration (d), and the contacting time (e, f) on the adsorption lead adsorption performance of SiPS-N($\left(\mathrm{CH}_{3}\right)_{3} \mathrm{Cl}$. Experimental conditions: (b) $\mathrm{t}=$ $1 \mathrm{~h},\left[\mathrm{~Pb}^{2+}\right]=500 \mathrm{mg} / \mathrm{L} ;(\mathrm{c}) \mathrm{t}=1 \mathrm{~h},\left[\mathrm{~Pb}^{2+}\right]=500 \mathrm{mg} / \mathrm{L},[\mathrm{HCl}]=1.0 \mathrm{M} ;(\mathrm{d}) \mathrm{t}=1 \mathrm{~h},[\mathrm{HCl}]=1.0$ $\mathrm{M}$; (e) and (f) $[\mathrm{HCl}]=1.0 \mathrm{M}$.

Fig.9 (a) The breakthrough curve of lead in $1.0 \mathrm{M} \mathrm{HCl}$; (b) Effect of $\mathrm{HCl}(1.0 \mathrm{M})$ volume on the lead concentration in the effluent; (c) Effect of flow speed on the chemical yield of lead; (d) effect of $\mathrm{FeCl}_{3}$ on the chemical yield of lead. Experimental conditions: $m$ (resin) $=3.3579$ g, column $\phi \times h=5 \mathrm{~mm} \times 30 \mathrm{~cm}$; Flow speed (a) = $2.0 \mathrm{~mL} / \mathrm{min}$, Flow speed $(\mathrm{b})=1.0 \mathrm{~mL} / \mathrm{min}$. 